\title{
PROSES TERBENTUKNYA DUKUNGAN KELUARGA KEPADA REMAJA PENYALAHGUNA NARKOBA YANG SEDANG DIREHABILITASI DI RSJ BANGLI
}

\author{
Made Dewi Sariyani ${ }^{` 2}$, Kadek Sri Ariyanti1 \\ ${ }^{1}$ STIKES Advaita Medika Tabanan, ${ }^{2}$ Pasca Sarjana Universitas Udayana \\ Korespondensi penulis: sariyani27@ymail.com
}

\begin{abstract}
Abstrak
Latar Belakang dan tujuan: Menurut UNODC (The United Nations Office on Drugs and Crime) dalam World Drug Report tahun 2015, estimasi pengguna narkoba pada tahun 2013 yaitu 246 juta orang, dimana jumlah kasus narkoba terbanyak terjadi pada penduduk berusia 15-64 tahun. Faktor terbesar yang dapat mempengaruhi keberhasilan pengguna narkoba untuk meninggalkan narkoba selamanya yaitu dengan niat yang kuat dari dalam diri dan dukungan keluarga yang positif. Penelitian ini bertujuan untuk mengetahui secara mendalam Proses Terbentuknya Dukungan Keluarga kepada Remaja Penyalahguna Narkoba yang sedang direhabilitasi di RSJ Bangli.

Metode: Rancangan penelitian ini menggunakan rancangan kualitatif. Data kualitatif dikumpulkan melalui teknik in-depth interview 12 informan, dimana terdiri dari 6 informan yaitu orang tua remaja penyalahguna narkoba yang sedang direhabilitasi, 3 orang perawat di Ruang Rehabilitasi, 3 orang remaja yang sedang direhabilitasi di RSJ Bangli.

Hasil: Pada penelitian ini, keluarga memiliki faktor internal dan eksternal serta hambatan dalam membentuk dan memberi dukungan kepada residen.

Simpulan: Dalam membentuk dukungan, keluarga memiliki faktor internal dan eksternal yang mempengaruhinya, selain itu keluarga juga memiliki faktor penghambat seperti rasa jenuh dan jarak rumah.
\end{abstract}

Kata kunci: proses, dukungan, keluarga, remaja, rehabilitasi

\section{Pendahuluan}

Menurut UNODC (The United Nations Office on Drugs and Crime) dalam World Drug Report tahun 2015, estimasi pengguna narkoba pada tahun 2013 yaitu 246 juta orang, dimana jumlah kasus narkoba terbanyak terjadi pada penduduk berusia 1564 tahun. Hasil proyeksi angka prevalensi penyalahgunaan narkoba di Indonesia pada tahun 2014 adalah sekitar empat juta atau setara dengan $2,2 \%$ dari populasi penduduk berusia 10-59 tahun yaitu 184.175 .000 orang ${ }^{1}$. Pada tahun 2014, Bali menjadi peringkat delapan untuk kasus penyalahgunaan narkoba dengan jumlah penyalahguna 66.785 orang atau bisa dikatakan setara dengan 2,2\% dari jumlah populasi penduduk yang usianya 10-59 tahun yaitu 3.008.900 orang ${ }^{2}$. Penelitian ini bertujuan mengetahui secara mendalam Proses Terbentuknya Dukungan Keluarga kepada Remaja Penyalahguna Narkoba yang sedang direhabilitasi di RSJ Bangli. Penelitian ini diharapkan mempunyai manfaat yaitu Penelitian ini diharapkan dapat menambah khasanah ilmu pengetahuan tentang proses terbentuknya dukungan keluarga kepada remaja penyalahguna narkoba yang sedang direhabilitasi, dan Penelitian ini diharapkan dapat digunakan sebagai dasar pertimbangan perencanaan program rehabilitasi penyalahguna narkoba di RSJ Bangli dan dapat digunakan sebagai pedoman tata laksana tenaga kesehatan yang 
melayani rehabilitasi narkoba. Dukungan keluarga adalah sikap, tindakan dan penerimaan keluarga terhadap anggotanya. Anggota keluarga dipandang sebagai bagian yang tidak terpisahkan dalam lingkungan keluarga $^{3}$. Motivasi adalah segala sesuatu yang mendorong seseorang untuk melakukan sesuatu $^{4}$. Faktor terbesar yang dapat mempengaruhi keberhasilan pengguna narkoba untuk meninggalkan narkoba selamanya yaitu dengan niat yang kuat dari dalam diri dan dukungan keluarga yang positif ${ }^{5}$.

\section{Metode Penelitian}

Penelitian mengenai Proses Terbentuknya Dukungan Keluarga kepada Remaja Penyalahguna Narkoba yang sedang direhabilitasi di RSJ Bangli menggunakan rancangan kualitatif. Pendekatan tersebut dipilih agar dapat mengeksplorasi peran keluarga dalam memberikan dukungan kepada penyalahguna narkoba secara lebih mendalam. Subjek penelitian ini adalah keluarga baik orang tua maupun saudara terdekat yang memberikan dukungan kepada penyalahguna narkoba yang sedang direhabilitasi di RSJ Bangli. Penelitian ini menggunakan 12 informan dimana terdiri dari 6 informan yaitu orang tua remaja penyalahguna narkoba yang sedang direhabilitasi, 3 orang perawat di Ruang Rehabilitasi, 3 orang remaja yang sedang direhabilitasi di RSJ Bangli.

\section{Hasil dan Pembahasan}

Dalam proses pembentukan dukungan keluarga, terdapat dua faktor penting yaitu faktor intrenal dan eksternal, serta hambatan.

\section{Faktor Internal}

Adapun faktor internal yang mempengaruhi informan dalam memberikan dukungan yaitu jenis kelamin, kondisi fisik, pengetahuan, pengalaman, dan spiritual edukasi dari tenaga kesehatan, seperti kutipan di bawah ini.

"kalau saya sempat drop, kaget denger anak saya begini, tapi bapaknya yang menguatkan saya, mungkin karena dia laki-laki ya dik, jadi lebih kuat ngasi dukungan ke saya dan anak saya......."IN-1.
“ mm... iya... saya berusaha tegar gek, kalau bukan saya siapa men lagi?bapaknya sakitsakitan. Ya jadi saya sama kakak-kakaknya saja dah yang ngurusin ini.... IN-4

"saya berusaha untuk tidak sedih nggih, saya banyak baca akhirnya, banyak juga temanteman yang bercerita tentang kejadian seperti ini, jadi memang kami sebagai orang tua apalagi saya bapaknya, saya harus kuat biar dia juga sadar, dan semangat untuk sembuh...” IN-5

"awalnya sedih pasti. Kalau kuat karena saya banyak mendengar pengalamanpengalaman keluarga yang anaknya direhab disini, katanya dukungan kita sebagai orang tua sangat penting, gitu dik....” IN-6

"kekuatan saya itu Cuma doa aja dik. Tiap saya mulai sedih inget ini, saya langsung sembahyang, ngambil dah saya dupa, langsung dah saya nangis,tapi setelah itu tenang jadinya saya...” IN-9

\section{Faktor eksternal}

Faktor eksternal yang diyakini keluarga mampu membentuk dukungan yang baik untuk remaja yang sedang direhabilitasi yaitu dukungan tenaga kesehatan, kebijakan Rumah Sakit, dan Lingkungan sosial

"kuat semenjak diberikan pengertian dan informasi, kan disini rutin kita orang tua diberitahukan perkembangan anak kita sama perawat disini, sama dokternya juga.... berguna sekali informasi itu buat saya..." IN 9

"Ya saya sangat berterima kasih karena sudah diberikan ijin boleh menjenguk anak saya $2 x$ dalam seminggu untuk tetap bisa mensupport dia..ya, biar cepet sembuh dan keluarlah dari sini... " IN-2

"tetangga sekitar sangat menentukan keadaan saya buk. Awalnya saya drop karena kan malu ya diomongin tetangga, tapi mereka akhirnya memberikan perhatian kepada saya, sampai akhirnya saya mengatakan kepada diri saya, kalau saya harus kuat..", IN-1

\section{Faktor Penghambat}

Adapun faktor penghambat dalam terbentuknya dukungan keluarga yaitu rasa 
jenuh yang dimiliki anggota keluarga karena residen selalu melakukan kekerasan fisik dan jarak rumah dengan tempat rehabilitasi.

" sampun med tiang galakine terus. Tempelenge tiang buk...”, IN- 2 (dalam Bhasa Bali),

"sudah bosan saya dimarahin terus, di tampar saya buk....”, IN-2

" ya pihak keluarga mungkin sudah bosan di kerasin terus, makanya akhirnya mereka berpikir, ya udahlah, biar saja dia disini, dan memang ada keluarga yang speerti itu tidak pernah menjenguk residen disini..", Perawat 1

"tidak tiap hari saya kesini, rumah saya di singaraja, jauh, jadi ya sebulan sekali saja...", IN 3

Harapan dari residen (remaja yang sedang direhabilitasi) yaitu keluarga tetap mendukung mereka untuk bisa pulih dari rehabilitasi.

"Support dari keluarga saya sangat perlukan dalam membangun penghargaan diri karena saya baru sadar keluarga adalah orang yang selalu ada disaat kita senang maupun sedih."Res-5.

Keluarga merupakan faktor terpenting yang mempengaruhi semangat penyalahguna narkoba. dukungan keluarga sangat diharapkan oleh para residen selama mereka berada di rehabilitasi ${ }^{6}$. Dalam memberikan motivasi atau dukungan seseorang dipengaruhi oleh faktor internal yang merupakan faktor dari dalam diri meliputi aspek fisiologis dan psikologis, sedangkan faktor eksternal merupakan faktor yang berasal dai luar diri meliputi aspek lingkungan sosial dan non sosial ${ }^{7}$. Sesuai teori precede procede, salah satu faktor yang menentukan perilaku yaitu presdiposisi (predisposing factor), dimana faktor predisposisi (predisposing factor) mencakup pengetahuan dari individu, sikap, kepercayaan, tradisi, norma sosial dan unsurunsur yang terdapat dalam individu dan masyarakat ${ }^{8}$. Pada penelitian ini, yang termasuk faktor presdiposisi yaitu pengetahuan, pengalaman, jenis kelamin, spiritual dan kondisi fisik.

\section{Simpulan}

Dalam membentuk dukungan, keluarga memiliki faktor internal dan eksternal yang mempengaruhinya, selain itu keluarga juga memiliki faktor penghambat seperti rasa jenuh dan jarak rumah.

\section{Referensi}

1. BNN. Data Kasus Narkoba. (BNNP Bali, 2016).

2. BNN. Survei Nasional Perkembangan Penyalahguna Narkoba. 4 (2014).

3. Zuhri, M. Proses Memilih Keputusan Pola Pikir Anak Remaja Dalam Menyelesaikan Masalah. 1-9 (2019).

4. Nursalam. Manajemen Keperawatan. (Salemba Medika, 2013).

5. Aztri.S., Milla, M. . Rasa Berharga dan Pembelajaran Hidup Mencegah Kekambuhan Kembali pada Pecandu Narkoba Studi Kualitatif Fenomenologis. Psikologi IX, (2013).

6. Sari, E. P. Hubungan antara Persepsi terhadap Keterampilan yang Dimiliki Dengan Self Esteem Eks Penyalahguna Napza di Balai Rehabilitasi Sosial Pamardi Putera Lembang. Fak. Psikol. (2016).

7. Setiawan. Hubungan Pengalaman Hidup dengan Resiliensi Pengguna Narkoba. (2009).

8. Faulkner, A. et al. Mental Health Peer Support in England: Piecing Together The Jigsaw. (2013). 